\title{
A ralé hidrica e a elite da água no semiárido brasileiro: a articulação entre o mercado dos carros-pipa, as cisternas residenciais, as hidrobiopolíticas e seus agenciamentos
}

\author{
Jairo Bezerra Silva ${ }^{1}$
}

Lemuel Dourado Guerra Sobrinho²

Ramonildes Alves Gomes ${ }^{3}$

Resumo: Neste artigo analisamos os modos de naturalização das desigualdades da escassez hídrica no semiárido brasileiro. As reflexões que fundamentam a discussão são feitas com base no debate sobre a ordem hidrossocial estabelecida na microrregião de Catolé do Rocha, no semiárido paraibano, com a realização de 30 entrevistas semiestruturadas, feitas entre os anos de 2017 e 2018, com informantes residentes nos diferentes municípios da microrregião citada. O trabalho de campo realizado apontou para paisagens marcadas pela injustiça hídrica e pela continuidade de biopolíticas hídricas e seus agenciamentos das ordens sociohídricas, as quais reproduzem a assimetria quanto à apropriação e acesso à água. Encontramos nos discursos dos entrevistados uma recorrente naturalização da "escassez de água"; evidências da intensificação do mercado de águas. Nas explicações dadas pelos sujeitos da pesquisa, destaca-se a tendência a aludir à causação religiosa das situações de escassez hídrica, associada a um

\footnotetext{
Universidade Estadual da Paraíba, campus IV, PLANDITES/UERN, Brasil - jairrobezerra@hotmail.com Universidade Federal de Campina Grande/PPGCS/UFCG, Brasil - lenksguerra@yahoo.com Universidade Federal de Campina Grande/PPGCS/UFCG, Brasil - rnildes@hotmail.com
} 
baixo nível de responsabilização das instâncias governamentais quanto ao enfrentamento das situações de desabastecimento de água.

Palavras-chave: Região Nordeste; crise hídrica estrutural; hidrobiopolíticas e seus agenciamentos

\section{The 'water rabble' and the 'elite of water': Articulations Among Water Trucks, Residential Cisterns, Water Biopolitics and their Agencyings}

Abstract: In this paper we analyze the ways of naturalizing inequalities in water scarcity in the Brazilian semiarid region. The reflections that underlie the discussion are based on the debate on the hydrossocial order established in the Catolé do Rocha microregion in the semi-arid region of Paraiba, Brazil, with data obtained through 30 semi-structured interviews between 2017 and 2018, with informants residents of the different municipalities of the mentioned microregion. The fieldwork carried out pointed to landscapes marked by water injustice and by the continuity of water biopolitics and their agencying of socio-hydraulic orders, which reproduce the asymmetry regarding the appropriation and access to water. We found in the interviewees' discourses a recurrent naturalization of 'water scarcity'; evidence of the intensification of the water market. The explanations given by the research subjects include the tendency to refer to the religious causation of situations of water scarcity, associated with a low level of accountability of governmental instances regarding the confrontation of situations of water shortages.

Keywords: Water Social Hierarchies; Water Justice; Water biopolitics and their Agencyings

\section{Introdução}

A água é algo por demais importante para ter sua gestão deixada nas mãos de burocratas do mercado ou mesmo de cientistas.

(Boelens, 2015)

O objetivo principal deste artigo é analisar a construção social dos discursos que convergem no sentido de naturalizar as recorrentes crises hídricas na região semiárida do Nordeste brasileiro, espaço social onde tem existido e se reproduzido secularmente uma hierarquia social referida ao controle e acesso à/da água. $\mathrm{O}$ estudo das questões que se referem à distribuição e acesso à água tem sido marcado por um viés individualizante, abordando os problemas de 
abastecimento hídrico como causados pelas formas como os indivíduos definem e adotam critérios para utilização dos recursos hídricos e não enquanto resultado das estratégias de gestão adotadas nos níveis meso e macrossociais. Assim, esse viés é objeto de problematização neste artigo.

Na região semiárida, as políticas públicas de gestão hídrica não têm se adaptado aos contextos sociogeográficos das populações locais, instaurando-se modelos baseados na premissa de que são as políticas que precisam se adaptar tanto aos modelos de manejo dos recursos hídricos tradicionalmente implementados quanto à escassez de água na região em que vivem. A discussão das fronteiras desiguais e das diferenças de acesso à água na região, resultante de formas tradicionais e contemporâneas de governança é atravessada por diversos reflexos da hegemonização de ideologias reprodutoras das estruturas hídricas regionais, aparecendo no espaço onde foi realizada a pesquisa cujos resultados apresentamos aqui.

Destaca-se nos discursos de atores que focalizam a questão hídrica na região a ênfase dos instrumentos econômicos de regulação do recurso, por meio da mobilização dos mecanismos da precificação da água, da redução de subsídios governamentais e instauração de mercados hídricos, apresentados enquanto instrumentos de inovação na governança da água, inscritos no cotidiano das populações em geral e nas dinâmicas dos Comitês de Bacias Hidrográficas (Silva, 2010; Martins, 2015).

Durante a pesquisa de campo, na qual realizamos 30 entrevistas semiestruturadas, entre os anos de 2017 e 2018, com informantes residentes em Catolé do Rocha/PB e outros municípios da microrregião citada, os sujeitos relataram que utilizam formas sistemáticas de racionamento da água há muito tempo e independente dos períodos de estiagem prolongada, historicamente conhecidos como de "seca". É importante destacar que, nas falas registradas sobre os problemas de acesso à água, não encontramos a visão de que eles se relacionariam a séries históricas de ação político/estatal, as quais têm produzido a estruturação do acesso à água na região estudada (ver localização no mapa a seguir).

Mapas do Município de Catolé do Rocha e do estado da Paraíba/Semiárido nordestino
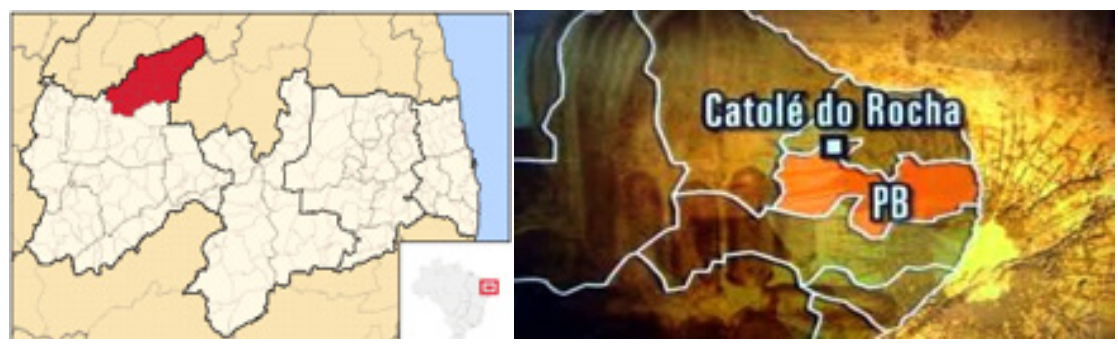

Fonte: www.google.com.br 
As ações estatais na área hídrica indicam uma articulação entre o Estado e os agentes do mercado, sendo marcadas por traços de clientelismo historicamente estabelecidos. Os discursos políticos sobre as questões do acesso e uso da água na região e os produzidos sob a classificação de científicos têm contribuído para a ocultação dos mecanismos que determinam os agenciamentos biopolíticos hídricos nela configurados, disseminando uma visão que ora responsabiliza a população dos alijados do acesso ao recurso - apontando para o que configuraria um uso irracional da água pelos indivíduos, ora a natureza, observando-se uma conjunção explicativa também marcada pela alusão a causas referidas à esfera da religião. Esses discursos têm sido utilizados para ratificar a solução mercantilista - o controle do acesso por meio da precificação da água - e para proteger do questionamento o campo técnico-burocrático estatal. Permanecem descartadas as alternativas de formulação de propostas de governança hídrica diferentes da realizada até o presente, as quais poderiam diminuir as assimetrias e disparidades concernentes ao acesso à água dos diferentes consumidores.

Nossa abordagem parte dos pressupostos da Ecologia Política da Água, aqui entendida como uma reflexão a respeito das relações de poder que moldam o conhecimento e as formas de delineamento de hidrobiopolíticas por parte do Estado, as quais resultam em formas de articular a natureza e as pessoas, em diferentes escalas, de modo a produzir ordens sociohídricas específicas, produzindo setores privilegiados e desprivilegiados. Essa matriz analítica enfatiza a distribuição desigual de benefícios e responsabilidades referidos à gestão e ao acesso à água.

As desigualdades sociais estruturais em termos de sociedades envolventes se refletem na hierarquização do acesso à água no semiárido em diversas escalas, baseada nas diferenças de classe, nos lugares onde os grupos humanos se fixam, na discriminação cultural/regional e na diferenciação de gênero. Neste artigo, discutimos em que medida o discurso de indivíduos e grupos que residem no sertão semiárido, atingidos diretamente por diversos vetores de hierarquização no que se refere ao acesso aos recursos hídricos, dão suporte à naturalização da crise hídrica estrutural e das estratégias baseadas na precificação do recurso que têm sido formuladas pelo Estado para o enfrentamento dos problemas de abastecimento hídrico.

Uma das ideias centrais deste trabalho é a de que o marco hidromercadológico, adotado pelo Estado e legitimado pela ciência como indispensável para o enfrentamento do cenário da "escassez hídrica" do semiárido brasileiro, contribui para potencializar a situação de injustiça hídrica na região mencionada. Como mostraremos a seguir, as vozes dos entrevistados e a interlocução entre 
a ideologia disseminada pelo mercado e pelo estado brasileiro endossam a naturalização da estiagem no semiárido brasileiro como um elemento central explicativo dos problemas de abastecimento de água historicamente enfrentados pelas populações pobres da região.

Na pesquisa que serviu de base para a produção do presente texto, buscamos apreender rotinas de acesso e uso de água das populações locais, por meio da realização de entrevistas abertas com informantes que constituíram uma amostra intencional de 30 indivíduos, estratificados proporcionalmente às camadas da população da área na qual é central o município de Catolé do Rocha/PB. Selecionamos sujeitos que compõem a "elite das águas", indivíduos das camadas abastadas da região citada, os quais não são afetados pelos recentes racionamentos de água; e sujeitos das ralés hídricas locais, aqueles que passam a depender dos carros-pipas, elementos que compõem o cenário local há décadas.

Os grupos sociais que integraram o universo da pesquisa foram compostos por agricultores(as) familiares, alguns com inserção na atividade pecuária, na sua maioria pessoas residentes nas zonas rurais. Alguns residem nas sedes urbanas dos municípios, mas desenvolvem suas atividades na zona rural. Buscamos entrevistar pessoas de três faixas etárias (jovens, adultos e idosos), com a intenção de observar de que maneiras os "flagelos" da seca no passado ainda ecoam no presente. Também foram incluídos na análise discursos de pessoas da classe média, os relativamente privilegiados; e de membros da elite da água, os que vivem perenemente com água assegurada, não importam as estiagens atravessadas pela região.

\section{A naturalização das experiências de exclusão hídrica}

Como observado em outras regiões do planeta, assistiu-se, ao longo da segunda metade do século XX, no Brasil, a uma crescente comodificação dos recursos hídricos, o que poderia se associar com a emergência de conflitos socioambientais no que corresponde ao acesso à água. Para Ioris (2013), a lógica do modelo de desenvolvimento hidrológico forjado no século XX, no Brasil, corresponde à história da flexibilização econômica ocorrida a partir dos anos 1990, observando-se a pressão para a privatização da gestão do abastecimento de água, uma das orientações dos organismos internacionais, desdobrando-se na intensificação da mercantilização da água, e também do saneamento básico no país.

A estratificação social no Brasil foi objeto de Souza (2009), resultando na tipificação da "ralé" brasileira, expressão com a qual o autor se refere ao 
status dos indivíduos excluídos dos direitos sociais básicos que legitimam a condição de cidadania. O termo "ralé" implica na situação de exclusão no que tange aos direitos sociais. Quando adicionada a qualificação "hídrica", indica-se a limitação de direitos experienciada quanto ao acesso à água de boa qualidade, apontando-se para um consumo restrito e abaixo dos níveis estabelecidos pela ONU em torno de 20 litros/per capita/dia, em contraposição ao que chamamos aqui de "elite hídrica", para expressar a sua potencialidade de apropriação de privilégios no que se refere ao acesso e uso de água de qualidade.

O uso aqui proposto da expressão "ralé hídrica" faz referência à solidificação de uma hierarquia dos privilégios em relação ao abastecimento de água, 0 que, no campo da sociologia rural, pode ser compreendido como a aquisição e uso de protocolos de cooptação dos usos múltiplos e sustentáveis da água, dependentes do poder que os indivíduos possuem de pagar o preço dos recursos hídricos em uma determinada escala social.

Acompanhamos Martins (2015) em sua compreensão dos novos arranjos de governança ambiental e de hidrobiopolíticas, das fronteiras da desigualdade entre atores sociais, hierarquicamente capitalizados, os quais repercutem nas rotinas diárias de acesso e uso da água, bem como na qualidade da participação popular nas instâncias dos comitês de bacias hidrográficas no Brasil.

Também partilhamos da concepção de Galizoni e Ribeiro (2011), segundo a qual a chamada "nova governança hídrica", inspirada nos princípios neoliberais, incorpora como alternativas ótimas para a racionalização do uso dos recursos a precificação dos recursos naturais, a redução de subsídios sociais e a consolidação dos mercados, instaurando a naturalização da hierarquização econômica do acesso à água.

Uma significativa fração da população brasileira tem sido subtraída em seu direito humano de acesso e uso da água. No contexto em que realizamos a pesquisa, esse direito se confunde com uma possibilidade de dádiva, a qual, quando ocorre, tem como contrapartida devida a lealdade eleitoral e a atribuição de honra e prestígio aos coronéis e empresários da água, agentes que se articulam para reproduzir a indústria dos carros-pipa e sua utilização como moeda de troca eleitoral.

Os problemas e soluções do abastecimento hídrico na região pesquisada continuam sendo vistos como referidos à "administração divina", à providência dos deuses. Vejamos como é descrito por alguns dos entrevistados o cenário de desabastecimento de água e a estratégia do abastecimento feito por carros-pipa, gerenciados pelo exército brasileiro, no sertão da Paraíba: 
Tomara Deus que chova. A água tá acabando. Nunca tinha visto faltar água desse jeito. Quem diria que o Rio Piranhas ia secar um dia? Olha, o povo tem que orar muito a Deus. Eu nunca tinha visto 5 anos de seca. (Agricultor familiar, 57 anos)

A nossa situação é bastante séria. Falta água até para beber. A população que vai até o cacimbão público tem que enfrentar enormes filas. Só Deus pra olhar pra nós e mandar chuva. (Agricultora familiar, 37 anos)

Na base do fenômeno da naturalização das diferentes apropriações dos recursos hídricos encontramos a mobilização dos elementos religiosos pelos indivíduos, o que em certa medida pode explicar o baixo nível de organização popular e de potencial mobilizatório para reivindicar o direito humano à água na região estudada. Dona Nega (agricultora familiar, 55 anos), uma das entrevistadas, menciona uma guerra pela água, mas indicando os conflitos entre os iguais nas instâncias de distribuição constituídas pelos carros-pipa, e não a mobilização da população que tem seu direito subtraído em relação às instâncias governamentais em seus diversos níveis.

Na concepção de Galizoni e Ribeiro (2011), a visão religiosa e construída com base em baixos níveis de instrução e mobilização política serve para disseminar e reproduzir a visão da secular apropriação dos recursos da natureza na área como apartada dos interesses políticos e dos arranjos sociais em que vivem a população da região.

Como identificado por Boelens (2015), a mobilização de símbolos religiosos nos discursos explicativos das paisagens hídricas ${ }^{4}$ é internalizada e incutida no imaginário das populações do campo, conforme os lavradores da Mantiqueira, do Jequitinhonha e do São Francisco, em Minas Gerais, fazendo com que estes percebam a água como dádiva e não como instrumento político. Em certa medida, tal procedimento sedimenta uma tendência de naturalização do mundo

4 Esse termo é uma tradução possível da expressão inglesa "waterscape", utilizada por vários estudiosos (Budds; Hinojosa, 2012; Heynen; Kaika; Swyngedouw, 2004; Swyngedouw, 2006; Swyngedouw, 1999; Zimmer, 2011; Zug; Graefe, 2014). Neste artigo, o conceito de paisagem hídrica segue o proposto por Swyngedouw (1999), segundo o qual os recursos hídricos são objetos de conflitos e relações de poder em um espaço físico e social - o que inclui relações socionaturais, de dominação e subordinação, de acesso e exclusão, de emancipação e repressão - no qual circulam diversos significados simbólicos e culturais referidos à água e seus usos. Esses espaços físico e social são coproduzidos com base em práticas diárias e negociações, resultantes das interações materiais e imateriais entre o ser humano e a água. Swyngedouw (2004: 29) defende que o desenvolvimento e modernização induzem à modificação das paisagens hídricas de forma contínua, fazendo-as "paisagens liminares" e as instaurando como arenas de disputa por poder e privilégios referidos à apropriação da água. 
social, regrado em suas contradições, ao tempo em que ratifica a tese de Souza (2018), sobre a qual vivemos sob o manto das teorias de média explicação, de baixo nível de complexidade e da viabilização do desocultamento dos mecanismos que produzem o mundo social.

A conjunção do processo da naturalização da restrição hídrica, em que vivem os indivíduos - que se desdobra em imobilismo no que concerne aos movimentos possíveis de reivindicação dos seus direitos à água junto ao Estado - com a força manipuladora das explicações religiosas acerca da escassez, conforma uma chave discursiva que une dominantes e dominados em seus discursos. Governos e elites aparentemente aceitam os direitos de todos à água, ao saneamento básico, todavia, apenas para assegurar a submissão dos que têm seu direito subtraído e para garantir as estruturas de movimentação da economia da troca de estratégias pontuais de abastecimento de água - a exemplo dos caminhões-pipas - pela lealdade política. Os excluídos do acesso digno aos recursos hídricos aparentemente se conformam com o que se lhes oferecem, colocando em curso estratégias de apropriação emergenciais que reproduzem entre eles, as estruturas de privilegiamento instituídas pelas elites em relação à "ralé hídrica".

\section{Os lugares na hierarquia hídrica e suas vozes}

A questão da anunciada escassez da água do semiárido brasileiro raramente tem sido tratada com base em uma reflexão que efetivamente transcenda os vieses hidromercadológico e hidrotécnico, na direção da abordagem dos aspectos sociopolítico-culturais dos problemas hídricos, das desigualdades estruturais do acesso e uso da água. Fazendo a crítica desse traço da abordagem predominante sobre as questões hídricas no Brasil, Martins (2015) ressalta que a "nova governança hídrica" instaura relações entre agentes e instituições sociais as quais se estabelecem com base em uma economia moral fundamentada nos princípios da gestão hídrica técnico-racional, enunciada como objetiva e neutra.

As paisagens hídricas são marcadas por uma intensa agonística referida à hidrobiopolítica e dos agenciamentos relativos ao controle da gestão, apropriação e consumo da água. A análise do funcionamento dos imaginários socioculturais de que se revestem os recursos hídricos, em seus fluxos e antifluxos relativos às lutas entre grupos de indivíduos pelos privilégios de apropriação da água, implica na descrição dos mecanismos determinantes da partilha dos benefícios e responsabilidades na esfera hídrica, na interpretação da agência de atores humanos e não humanos e nos modos pelos quais ela é justificada por meio de dispositivos discursivos referentes à tecnologia, à cultura, à "hidrobiopolítica", 
Argumentamos aqui que as dinâmicas sociohídricas sejam focalizadas em termos das hidrobiopolíticas e da "governamentalidade hídrica" em suas diversas manifestações históricas e espaciais. Com as duas expressões inspiradas na reflexão foucaultiana sobre saber-poder-subjetividade anterirmente utilizadas, propomos uma abordagem dos modos de justificação do acesso hierarquizado aos recursos hídricos e de suas consequências no que diz respeito à qualidade de vida e desenvolvimento em termos da análise de regimes de representações que têm como objetivo governar a sociedade, definindo as questões hídricas de modo a dar sustentação aos princípios hierarquizadores dos arranjos sociais em cujo âmbito emergem as "ordens sociohídricas".

As referidas ordens e os imaginários que as sustentam se intermoldam, envolvendo a construção social de representações de fluxos de água, de sua distribuição e das regras e procedimentos de manejo hídrico nas diferentes escalas consideradas. As construções discursivas sobre os ciclos sociohídricos, eloquentemente apresentadas como fundamentadas na racionalidade e na técnica, operacionalizam a reprodução dos interesses de atores mais poderosos nas relações de forças que clivam as paisagens sociohídricas.

Nas camadas populares, o acesso a informações sobre os direitos sociais e a compreensão destes é geralmente baixa, sendo o senso comum, a mídia e a escola fatores eficazes de conservação e reprodução do status quo hídrico, na medida em que plausibilizam e legitimam as desigualdades sociohídricas.

$\mathrm{Na}$ base da pirâmide social brasileira e em especial na região semiárida do Nordeste, o conformismo social alimenta a desresponsabilização do Estado em todas as áreas, não sendo a esfera dos recursos hídricos uma exceção. $\mathrm{O}$ direito universal à água é reconhecido de modo incipiente, pavimentando o terreno para a concepção das ações estatais esporádicas e emergenciais como dádivas dos agentes públicos. O que era para ser a distribuição democrática e racional é recorrentemente encarada como uma concessão, um favor dos governantes. $\mathrm{O}$ clientelismo baseado em estratégias de fornecimento pontual de abastecimento de água tem se reproduzido sem solução de continuidade. Vejamos no trecho da fala de uma das senhoras entrevistadas, que recebe água dos carros-pipas fornecidos pelo poder municipal, como se operacionaliza a economia da troca de água por lealdade eleitoral:

Rapaz, o negócio aqui por água está de mal a pior. As torneiras secaram. Nem comprando água você consegue. Eu mesma esperei oito dias para comprar quinhentos litros de uma água não muito boa. Ah, mas o prefeito daqui é bom, coloca água no carro pipa para quem quiser. (agricultora familiar, 49 anos) 
Esse exemplo aponta para o funcionamento do imaginário dos indivíduos da "ralé hídrica": a frase "mas o prefeito daqui é bom" indica como as ações do gestor municipal para o provimento pontual de água, distribuída por carros-pipas, obedecendo à priorização dos habitantes favoráveis a ele, e atendendo de modo precário e reprodutor da dependência dos indivíduos no que se refere ao acesso à água, lhe permite acumular capital político. No período eleitoral, a assistência ineficiente em termos de garantia do direito universal à água será cobrada em termos de votos, reproduzindo-se a desresponsabilização do Estado - em suas diversas escalas - em relação ao enfrentamento adequado dos problemas da falta e da qualidade da água provida aos habitantes das áreas afetadas pelas estiagens ou pelo desabastecimento estruturalmente determinado.

Como já afirmado, completando o conjunto de elementos discursivos mobilizados para a explicação da causalidade e eventuais estratégias para enfrentar os problemas de desabastecimento hídrico na região do semiárido brasileiro, encontramos a mediação oferecida pelo imaginário religioso regional, segundo o qual os índices pluviométricos observados nos municípios pesquisados seriam o resultado da "vontade de Deus", de dinâmicas relativas à esfera da religiosidade/espiritualidade.

Nas entrevistas realizadas na pesquisa, encontramos na maioria dos sujeitos a alusão à relação entre chuva ou ausência dela com a vontade de Deus, a permissão de Deus. Tanto os entrevistados católicos como os evangélicos mencionaram de algum modo como variável independente causal das estiagens e dos problemas por elas causados a "vontade de Deus". Com base nesse tipo de concepção, é fértil o terreno para que se desviem os indivíduos de eventuais estratégias reivindicatórias dirigidas ao Estado em suas diversas escalas, quando se interroga a respeito dos problemas de desabastecimento hídrico na região pesquisada. A força da explicação religiosa do mundo e dos fenômenos socionaturais em geral media a construção de sujeitos prontos para a conformação e pouco afeitos à luta por direitos em quaisquer das áreas da vida social e especificamente o direito ao acesso à água em quantidades e com qualidade adequadas. Sobre a presença dos aspectos religiosos nos discursos sobre a situação comum de iminente desabastecimento de água, cabe citar o trecho da entrevista citado a seguir, recorrentemente escutado no trabalho de campo:

[...] se Deus abençoar com bom inverno, nós não têm esses aperreios mais. Porque aperreio mesmo é a falta de água, que lá em casa tô comprando uma pipa de $15 \mathrm{em} 15$ dias pra tudo, beber, fazer comida, lavar roupa, casa... E o pior que o meu dinheiro do Bolsa Família vai todo embora. A gente deixa de 
comer pra beber, mas fome a gente passa, agora sede não tem quem aguente. (agricultor familiar, 38 anos)

Pesquisas referidas ao espaço urbano apontam para modelos diversos de hierarquização hídrica, os quais definem os modos de afetação dos indivíduos em cenários de desabastecimento nas cidades (Boelens et al., 2015; Boelens, 2015; Del Grande et al., 2016), o que é também observado na área pesquisada. Os grupos identificados aqui como da "ralé hídrica" correspondem àqueles que dependem dos carros-pipa, fornecidos ao sabor dos interesses dos governantes em várias instâncias; a "elite hídrica" perfura poços particulares, seguindo quase incólumes aos contextos de desabastecimento observados na região pesquisada, como vemos no trecho de entrevista realizada com uma senhora, profissional liberal, 45 anos: "Ah, lá em casa eu não sei o que é falta de água, o poço está resolvendo todos os nossos problemas, é muita água e dá para tudo: lavar carro, calçada, encher os reservatórios, irrigar as plantas e demais necessidades".

Do lado dos da "ralé hídrica", a direção da fala é outra:

Não temos caixa de água ou cisterna. O que a gente usa para se virar, quando falta água, é um balde de 100 litros, para guardar água. A gente sempre usa esse balde, e depois que o racionamento começou, a gente usou mais ele. E a gente também comprou mais um balde menor... Nada mudou com o racionamento, a gente continua economizando água, como sempre. Eu reuso a água de lavagem de roupas e do banho na limpeza de piso, de dentro e de fora [da casa], e na descarga do vaso [sanitário]. (Empregada doméstica, 55 anos)

Em algumas das cidades que visitamos durante a pesquisa de campo, encontramos longas filas de indivíduos à espera dos caminhões pipa, sob um sol causticante, repetindo uma paisagem que segue quase inalterada há cerca de um século. Nesse cenário, a indústria dos carros-pipa permanece robusta e a ineficiência de programas como o P1MC - uma das recentes hidrobiopolíticas públicas, consistindo em uma Programa de construção de cisternas residenciais no semiárido brasileiro - se evidencia, reproduzindo a ralé hídrica estrutural na região citada, correspondente à ralé estrutural urbana nas grandes cidades do país (Souza, 2009), formadas dos que saíram do campo em busca da cidade ideal, encontrando a cidade real dos excluídos das periferias.

Os que estão nas filas à espera da água são os que formam a "ralé brasileira", a "ralé hídrica brasileira". Os cenários são similares aos descritos por Graciliano Ramos em Vidas Secas, e por Rachel de Queiroz, em O Quinze, há décadas, reproduzindo como congeladas as paisagens de desolação e miséria da ralé hídrica da região. 
Mesmo reconhecendo que nos períodos de estiagem não se observam filas de retirantes, grupos de saqueadores e de flagelados, como o que encontrávamos na segunda metade do século XX, no Brasil, o acesso desigual aos recursos hídricos no semiárido do nordeste brasileiro ainda é intenso. Junto com essa continuidade, assistimos à intensificação do comércio de água: o das grandes empresas de água mineral; o dos fornecedores de carros-pipa; e dos pequenos vendedores, conforme registramos a seguir na fala de um dos entrevistados: "Eu compro água no poço de Zé Mole, a caixa de 1 mil litros custa 8 reais no poço, aí eu vendo aqui em Brejo por 20 reais a caixa fechada, e em Jardim eu vendo por tambor a 1,50 cada. Aqui em Brejo, eu vendo 6, 7, até 10 caixas por dia”' (desempregado, 52 anos).

Narrativas como esta indicam como o mercado hídrico é algo naturalizado, substituindo de modo célere a tradicional imagem da água como um recurso natural, por outra da água como uma mercadoria como qualquer outra. Vender e comprar água na região em estudo aparece como uma situação corriqueira, comum e socialmente aceita, obnubilando uma problemática para a qual os governos que se sucedem não têm apresentado soluções efetivas, de modo a produzir equidade hídrica.

De acordo com as entrevistas realizadas com indivíduos das camadas abastadas na região pesquisada, o que acontece são práticas de demarcação de classe mediadas pelo tipo de acesso à água, sendo sua apropriação e consumo instâncias que dão ou tiram a distinção social: a posição social é marcada pelo tipo de água e as quantidades que os diferentes indivíduos e grupos consomem. Isso pode ser expresso nas seguintes falas: "posso pagar e, por isso, não confio naquela água [a que é fornecida pelos caminhões-pipa]. Aqui em casa não falta água para nada e só consumimos água mineral” (Advogada, 42 anos).

Essas narrativas daqueles posicionados do outro lado da fronteira confrontam a fala do vendedor anteriormente citada. A estratificação social se revela por meio de qual e quanta água se pode comprar e consumir; da capacidade de armazenamento e nas rotinas de seu uso. Quanto maior a quantidade de capital social, econômico, político e cultural, melhor e mais água se pode acessar.

A fala de outro vendedor de água entrevistado ilustra esse tipo peculiar de estratificação hídrica: "Eu vendo 5 pipas d'água por dia. Acordo de duas horas da manhã, tenho 3 carroças, encho no cacimbão da prefeitura e faço retaio nas casas do povo, uma a uma. Cada lata dessa é 1 real" [sic].

A fala anterior revela a consciência quanto à existência de indivíduos capitalizados, os quais se constituem em público-alvo para o vendedor. Esses podem comprar água em abundância, e avaliar a origem (e a qualidade) do líquido. Poderíamos falar no sistema de inclusão/exclusão hídrica, dividindo-se a 
sociedade entre aqueles que podem e aqueles que não podem comprar água em grande quantidade; aqueles que podem e os que não podem exigir qualidade quanto à água consumida. A estes só resta a compra fracionada de água e sem a garantia da origem (qualidade), legitimando assim sua condição de ralé hídrica.

Nesse caso, apresenta-se a lógica global da estratificação mediada pelo consumo em geral, segundo a qual os indivíduos podem ser classificados em consumidores de primeira, segunda e terceira ordem. O que se observa em termos macrossociais se replica em relação ao consumo de água.

Em outra direção, uma agricultora familiar entrevistada apontou para a ineficiência da empresa responsável pelo tratamento e distribuição da água na Paraíba:

Eu vou mandar a CAGEPA cortar minha água. Pago 35 reais por mês e não tenho água. Quando chega ainda tenho que puxar na bomba. Quer dizer, pago água e ainda gasto energia elétrica pra ter acesso.

O território hidrossocial do semiárido brasileiro - uma materialização espacial no nível do imaginário e do cenário socioambiental de uma rede de interdependências na qual os indivíduos são dispostos e administrados; os recursos hídricos são geridos; a infraestrutura hidráulica é pensada e implementada; as políticas de financiamento relativas ao enfrentamento dos problemas relativos a ocorrências de desabastecimento são formuladas e implementadas; os arranjos administrativo-legais destinados a controlar o manejo dos recursos hídricos são delineados; a cultura e as práticas são definidas, alinhadas e legitimadas por meio de sistemas de crenças, hierarquias políticas e discursos naturalizadores.

Comparando os discursos dos entrevistados estratificados por faixa etária, as falas de pessoas idosas trazem uma relativa semelhança com os relatos das pessoas mais jovens. Vejamos um exemplo disso, comparando a fala de um senhor com mais de 90 anos, que reside hoje na região de Catolé do Rocha-PB com outra de um jovem agricultor:

Meu filho, essas pragas desses políticos tiravam proveito da nossa fome e sede. Nas secas nóis era obrigado a trabalhar de graça a troco de rapadura preta e farinha azeda. Água, meu filho, eu ia buscar um galão de água com meia légua e o resto ficava prá pobre da minha muié e de Aninha, minha filha mais velha, ir buscar na cacimba. E os políticos nunca fazia um poço nem um açude, e quando faziam um açude se agente bebesse da água tinha que votar no canidato do patrão, porque o açude só era feito em terras de gente rico essa gente de gravata nunca gostou da gente só queria o nosso voto. [sic] (Agricultor familiar, 85 anos) 
Aqui no sítio a situação é difícil, os poços secaram, o açude tá seco e se a gente quiser água até para os bichos beber, tem que comprar do carro pipa, por duzentos reais. As cisternas que o governo construiu estão na frente das nossas casas, mas a água para elas se não vêm do céu, a gente tem mesmo de comprar. (Agricultor familiar, 35 anos)

Os dois relatos indicam que os antigos problemas relacionados à "falta" de água não foram sanados, eles estão vivos e com nova roupagem. Eles apontam para o que Furtado (2013) nos alerta no que se refere ao subdesenvolvimento da região semiárida nordestina quando diz que "[...] a seca é consequência (e não causa) da questão sertaneja. A causa era a estrutura social e econômica que ali se reproduzia há séculos [...]”. Esse autor já questionava a naturalização das secas e destacava o caráter estrutural dos problemas delas decorrentes na região em que pesquisamos.

Em outra residência entrevistamos pai e filha, encontrando também pontos de convergência nas descrições dos problemas de abastecimento de água enfrentados: "Quando eu era moço as coisas era bem difícil. Nóis ia buscar água em um jumento com uma légua quando era ano de seca" [sic]. Sua filha comenta que: "É, meu pai, o senhor tem que ver que naquele tempo pelo menos a água era de graça. Era longe, mas era de graça, e hoje a gente gasta parte de sua aposentadoria pra comprar água”.

A ausência de uma governança democrática da água, que enfrente o problema como uma questão pública, abre as portas para o mercado de águas, que toma para si, em termos ideológicos, a tarefa de agente mediador para a solução dos problemas de acesso e uso dos recursos hídricos na região.

A estiagem e a instrumentalização de ações políticas de enfrentamento aos problemas causados por ela compõem o cenário que atravessa séculos, reproduzindo situações de injustiça hídrica e os altos níveis de vulnerabilidade hídrica de amplos setores da população do semiárido nordestino. Essa realidade fica bem expressa na fala de uma agricultora familiar de 45 anos, nos seguintes termos:

Na seca de 93, os meninos foram embora tudo pro mundo. De lá prá cá, eu só vi "Zein" uma vez, quando ele veio aqui em 99 e pronto. Os outros 2 ainda tão bolando pelo mei do mundo. Sem estudo, também não arrumaram nada, só sofrimento. Por isso que o meu eu coloquei logo pra estudar. [sic]

A fala da agricultora ressalta uma trajetória de dor, na qual pessoas se perdem com poucas chances de reencontro. Ou seja, ontem viviam cá, hoje vivem lá e distante dos espaços sociais originários de onde foram expulsos. A 
entrevistada até tenta ressaltar que hoje o acesso à água é mais fácil, mas o fato é que essa facilidade precisa ser criticamente analisada, visto que, se por um lado iniciativas como as cisternas de placa reduziram o sofrimento das famílias, possibilitando algumas melhorias no acesso à água para beber e para realizar os afazeres domésticos (lavar roupa, limpeza da casa etc.); por outro lado, as ações não oferecem segurança hídrica suficiente para viabilizar as atividades agrícolas e pecuária.

Com a recente implementação do projeto de transposição de águas do rio São Francisco, que entrecorta parte da região semiárida, problemas de abastecimento de água continuam:

Meu filho, quando eu era menino meu pai já falava dessa água que os governos falavam em trazer pra gente. Hoje eu sou um velho, já carreguei água em galão, jumento e carroça de boi até com duas léguas. Essa água chegou, mas nós não pode pegar dela livremente. Parece que só Deus tem piedade da nossa situação mandando chuva, os homens dessa terra não ligam em fazer nada. Só têm promessa de quatro em quatro anos. Essa água chegou, mas vem pelas terras dos ricos prá beneficiar eles mesmos e nós pobres tem que comprar a água cada vez mais cara. [sic]

Em um dos trechos da sua fala, "parece que só Deus tem piedade da nossa situação mandando chuva", o senhor deixa visível sua descrença em relação às pessoas e instituições que, em tese, deveriam equacionar de maneira racional e democrática o uso e o acesso à água. Outro recorte, "[...] Essa água chegou mas vem pelas terras dos ricos pra beneficiar eles mesmos e nós pobres têm que comprar a água cada vez mais cara", o senhor ressalta as tensões - sobre as quais pesquisas em andamento sobre os impactos da transposição no acesso e usos da água na região atendida em breve trarão dados mais completos - indica a percepção de que o espectro do velho e duradouro clientelismo ronda o cenário das correntes políticas governamentais de enfrentamento de problemas de desabastecimento hídrico, podendo seus sinais serem observados, por exemplo, na emergência e disseminação do "paradigma da convivência com o semiárido".

Outra narrativa, de uma senhora que labuta desde os 10 anos de idade na roça, vai na direção da solução individual da segurança hídrica:

Meu senhor, desde criança que eu trabalho na roça. Nunca aprendi a ler, pois tinha que ajudar no roçado que a família era grande. Desde pequena eu botava água na cabeça pra beber e cozinhar. Casei e o sofrimento continuou. Cansada de esperar pelos políticos, eu e meu marido resolvemos vender uns 
bichinhos e cavar um poço pra ver se as coisas melhoravam. Deus nos abençoou que o poço deu muita água e é doce, dá pra beber e cozinhar. Hoje temos água em casa pra tudo. (Agricultora familiar, 48 anos)

Como vemos na fala citada, a reação à ineficiência do Estado pode constituir saídas individualistas para que se garanta a segurança hídrica. Em uma conjunção entre a visão religiosa dominante e a possibilidade de resolução particular do problema, a entrevistada aponta para uma tendência a um baixo envolvimento com movimentos coletivos, de reivindicação política referida às esferas governamentais, o que pode ser entendido como um dos resultados não planejados da ação intensa de ONGs, no que se enunciou como as "novas estratégias de enfrentamento da questão hídrica" na região pesquisada (Targino, 2017).

Vale destacar a parte final do depoimento anterior, na qual a entrevistada complementa: "[...] hoje temos água em casa pra tudo só gasto com a energia da bomba, pois eu planto coentro, tomate, alface e mamão, vivemos disso, temos o nosso sustento e não precisamos pedir mais água aos políticos que só dão uma pipa d'água a quem vota neles". Nesse momento, vimos na expressão estampada em seu rosto enquanto falava o brilho nos olhos, presente pelo fato de ter conseguido uma relativa autonomia em relação ao controle velado e à dependência cultivada eufemisticamente pelos "coronéis políticos da água", figuras seculares do semiárido brasileiro.

\section{Considerações finais}

As entrevistas e série de observações diretas durante a pesquisa de campo na qual se baseia este artigo indicam a continuidade de limitações que têm marcado o acesso e uso à água para grandes faixas da população na região semiárida do nordeste brasileiro. A persistência de elementos tradicionais da paisagem hídrica da região citada - a exemplo dos caminhões-pipas -, bem como a reemergência das cisternas, apresentadas como soluções para a questão hídrica regional, apontam para uma visão que, mesmo se enunciando por meio de discursos de novidade, quer seja usando o léxico das "novas tecnologias sociais", quer seja por meio da disseminação de uma ruptura da série histórica das intervenções governamentais em termos de políticas hídricas para a região inscritas no âmbito do novo "paradigma de convivência com a seca", ou de "convivência com o semiárido", concluímos que temos no semiárido brasileiro a continuidade de biopolíticas hídricas cujos agenciamentos resultam na reprodução de hierarquias antigas relativas ao acesso à água. 
Nossa pesquisa apontou para uma ordem sociohídrica que repete a estratificação hídrica historicamente observada na região, apresentando-se em termos de uma pirâmide em cujo ápice se encontra a "elite hídrica" regional - formada por aqueles indivíduos que passam incólumes por períodos de intensa estiagem -, e em cuja base se encontra a maioria da população, suscetível às intempéries dos fenômenos naturais, frequentadores das filas de espera pela água que vêm dos carros-pipas, experimentando níveis sub-humanos de consumo hídrico, proprietários de cisternas distribuídas pela atuação articulada de ONGs e do Estado, mas que não têm condições de mantê-las com o volume de água suficiente nem a qualidade da água quando estão abastecidas.

As estratégias governamentais e não governamentais para o enfrentamento da questão hídrica do semiárido brasileiro são marcadas por uma visão presente em outras áreas de ação social do Brasil, segundo a qual o modo de endereçamento para as camadas pobres da população determina a proposição do inaceitável vestido de agência moderna e inovadora. Outro traço desse modo de endereçamento de grande parte de políticas públicas sociais no Brasil, em geral, e as concernentes à esfera hídrica, é a intenção velada da reprodução da dependência e das estruturas de dádiva e retribuição, delineadas de modo a fortalecer sistemas tradicionais de lealdades políticas.

Somada à estratificação sociohídrica que se perpetua na região, observamos o movimento paralelo entre a biopolítica hídrica e seus agenciamentos e as dinâmicas do mercado de águas, em um cenário em que se reproduzem processos de naturalização da estiagem, mediados, inclusive, pela centralidade da visão religiosa na cultura regional. Esses processos se conjugam com os baixos níveis de mobilização social relativa às reivindicações dos direitos hídricos, alimentando o ciclo que culmina com a continuidade da ineficiência do Estado no que se refere à formulação e implementação de hidrobiopolíticas públicas capazes de oferecer soluções efetivas aos problemas de desabastecimento de água no semiárido nordestino.

A consciência coletiva em que se forma a maioria dos indivíduos da região pesquisada contribui para a reprodução do hidro status quo, na medida em que prevalecem concepções que associam o acesso à água a dinâmicas da esfera da religião e como um direito não universal, mas apenas para poucos - os da "elite hídrica". Para a "ralé hídrica", o acesso à água, mesmo quando representando um risco de comprometimento do orçamento familiar, e que "dê para as atividades de limpeza e garantia de parte do plantio" muitas vezes apareceu nas entrevistas como um privilégio.

No que concerne às políticas hídricas públicas - as hidrobiopolíticas e seus agenciamentos -, a implementação de medidas pontuais, de caráter paliativo, 
para o enfrentamento de problemas de abastecimento de água tem sido formuladas com base em um escopo limitado no que tange à construção de situações de sustentabilidade hídrica - com o predomínio da indústria dos carros-pipa e do investimento na construção de cisternas de placa e polietileno, ou com a introdução de dessalinizadores - marcados por um vício de origem: o endereçamento para as camadas pobres da população, o que se traduz na tomada de medidas aceitáveis para os "outros", aqueles que "não precisam ter água encanada em casa”, que "têm força física para carregar nas costas as latas d’água", os que "podem se submeter a longas filas de espera pelos carros-pipas".

Em termos de visibilização social dos problemas de abastecimento de água, a espetacularização midiática dos cotidianos precários relativos ao uso de água continua produzindo e reproduzindo a naturalização do estigma geográfico quando se trata de "crises hídricas": circulam com abundância as imagens dos flagelados do nordeste; das vítimas, quando elas acontecem no sul/sudeste.

Concluímos remetendo o leitor para a epígrafe deste artigo, ao mesmo tempo em que propomos uma agenda de pesquisa que possibilite a produção de compreensões mais amplas das múltiplas camadas e desafios para a construção da justiça hídrica na região pesquisada. Para isso, são passos importantes: (1) repoliticizar a análise da apropriação do acesso aos recursos hídricos. Sem o estremecimento da orientação predominante no campo acadêmico e nas realidades pesquisadas no sentido de pensar as questões hídricas mais gerais e as específicas com base na concepção hidrotécnica, será difícil atuar sobre as ordens sociohídricas focalizadas. As análises que desconsideram a ecologia política das políticas hídricas contribuem para a reprodução da injustiça hídrica nas regiões analisadas; (2) pensar a governança hídrica em termos de hidrobiopolíticas e seus agenciamentos relacionados com a reprodução de privilégios e desprivilegiamentos de grupos de indivíduos. Essa conceituação aponta para a formulação dos problemas de pesquisa considerando a esfera política, o conceito de direitos hídricos e os sistemas de representações e discursos relativos à água. A mobilização desse léxico analítico possibilita pensar a ecologia política das águas, introduzindo nas pesquisas a interface entre as paisagens hídricas locais e regionais no contexto das dinâmicas de expansão global do capital; e (3) fazer flamejar, com o aporte de abordagens que repolitizem a questão hídrica em seus aspectos globais e repercussões locais, o cotidiano das injustiças hídricas em que amplos setores da população do semiárido são lançados, e seus efeitos em termos de políticas de acomodação, como o encontrado em nosso trabalho de campo, bem como na produção acadêmica especializada. 


\section{Referências}

ANDRADE, Jucilaine Aparecida de; NUNES, Marcos Antônio. Acesso à água no Semiárido Brasileiro: uma análise das políticas públicas implementadas na região. In: Revista espinhaço, 2014, v. 3, n. 2, pp. 28-39.

BAUDRILLARD, Jean. A sociedade de consumo. Portugal, Edições 70, 2008.

BOELENS, Rutgerd; PERREAULT, Tom; VOS, Jeroes. (Eds.) Water Justice. Cambridge, UK; Cambridge University Press, 2018 (378).

BOELENS, Rutgerd et al. Hidrosocial Territories and Water Governance Systems: An Introduction. In: Special Issue, Water International, Winter, 2015.

BOELENS, Rutgerd. Water Justice in Latina America: the politics of Difference, Equalty an Indifference. Amsterdam, CEDLA, 2015 (46).

BUDDS, Jessica; HINOJOSA, Leonith. Restructuring and Rescaling Water Governance in Mining Contexts: The Co-Production of Waterscapes in Peru. In: Water Alternatives, V. 5, n. 1, pp. 119-137, 2012.

DEL GRANDE, Maria Helena et al. A percepção de usuários sobre os impactos do racionamento de água em suas rotinas domiciliares. In: Ambiente e sociedade [online]. 2016, v. 19, n. 1, pp.163-182.

DUTRA, Camila Kayssa Targino. O papel da Articulação Semiárido Brasileiro (ASA) e o Programa $1 \mathrm{~m}$ Milhão de Cisternas (P1MC) no semiárido potiguar. Dissertação apresentada ao Programa Regional de Pós-Graduação em Desenvolvimento da UFRN, 2017.

FOUCAULT, Michel. A Ordem do Discurso. Aula inaugural no College de France. Pronunciada em 2 de dezembro de 1970. 22 $2^{\text {a }}$ ed. São Paulo, Edições Loyola - SP, 2012.

FURTADO, Celso. Essencial. Organização, apresentação e notas de Rosa Freire d’Aguiar. $1^{\mathrm{a}}$ ed. São Paulo, Penguin Classics Companhia das Letras, 2013.

GALAZONI, Flávia Maria; RIBEIRO, Eduardo Magalhães. Bem comum e novos costumeiras: a ética das águas em comunidades rurais de Minas Gerais. In: Ambiente \& Sociedade. Campina V. XIV, n. 1, pp. 77-94, jan-jun 2011.

HEYNEN, Nik; KAIKA, Maria; SWYNGEDOUW, Erik. In the Nature of Cities: Urban Political Ecology and the Politics of Urban Metabolism. [S.l: s.n.], v. 28, 2006. Disponível em: <http://bellwether.metapress.com/openurl.asp?genre=article\&id= doi:10.2747/0272-3638.28.2.206>. Acesso em: 11 set. 2019.

IORIS, Antônio Augusto Rossotto. Água, Exclusão, Mercado e Cobrança: um debate necessário. In: I Simpósio de Recursos Hídricos do Sul-Sudeste, 2006.

IORIS, Antônio Augusto Rossotto; COSTA, Maria Angélica Marciel. Até a última gota: complexidade hidrossocial e ecologia política da água na baixada fluminense (RJ, Brasil). In: $O$ direito à água como política pública na América Latina: uma exploração teórica e empírica/ editores: José Esteban Castro, Léo Heller, Maria da Piedade Morais. Brasília, Ipea, 2015, pp. 109-128 (322). 
IORIS, Antônio Augusto Rossotto. Na contracorrente dos recursos hídricos: água e ambiente no Brasil contemporâneo. In: Revista Crítica de Ciências Sociais, 85, Jun. 2009, pp. 23-41.

LATOUR, Bruno. Jamais fomos modernos. Rio de Janeiro, Editora 34 associada à Nova Fronteira, 1994 (192).

QUEIROZ, Rachel de. O Quinze. 102 ${ }^{\mathrm{a}}$ ed. Rio de Janeiro, 102 ${ }^{\mathrm{a}}$ ed. José Olímpio, 2016.

RAMOS, Graciliano. Vidas secas. São Paulo, Record, 2010.

SEN, Amartya. Desenvolvimento como liberdade. São Paulo, Companhia das Letras, $2010(464)$.

MARTINS, Rodrigo Constante. Fronteiras entre desigualdade e diferença na governança das águas. In: Ambiente e Sociedade, Campina, v. XVIII. n. 1, pp. 221-238, jan-mar., 2015. SILVA, Jairo Bezerra; GUERRA, Lemuel Dourado; IORIS, Antonio; GOMES, Ramonildes Alves. Conflitos sociopolíticos, recursos hídricos e programa um milhão de cisternas na região semiárida da Paraíba. In: Novos Cadernos NAEA, v. 18, n. 2, pp. 69-92, jun-set., 2015.

SOUZA, Jessé (org.) A ralé brasileira: quem é e como vive. Belo Horizonte, Editora da UFMG, 2009.

SWYNGEDOUW, Erik. Modernity and Hybridity: Nature, Regeneracionismo, and the Production of the Spanish Waterscape, 1890-1930. In: Annals of the Association of American Geographers, v. 89, n. 3, pp. 443-465, 1999.

SWYNGEDOUW, Erik. Social power and the urbanization of water - Flows of power. Oxford, Oxford University Press, 2004.

ZIMMER, Anna. Everyday governance of the waste waterscapes: a Foucauldian analysis in Delhi's informal settlements. 2011. Rheinische Friedrich-Wilhelms-University of Bonn, 2011. Disponível em: <http://hss.ulb.uni-bonn.de/2012/2956/2956.pdf>. Acesso em: 11 set. 2019.

ZUG, Sebastian; GRAEFE, Olivier. The gift of water: social redistribution of water among neighbours in khartoum. In: Water Alternatives, v. 7, n. 1, pp. 140-159, 2014.

Recebido em: 17/02/2018

Aprovado em: 04/07/2019

\section{Como citar este artigo:}

SILVA, Jairo Bezerra; SOBRINHO, Lemuel Dourado Guerra e GOMES, Ramonildes Alves. A ralé hídrica e a elite da água no semiárido brasileiro: a articulação entre o mercado dos carros-pipa, as cisternas residenciais, as hidrobiopolíticas e seus agenciamentos. Contemporânea - Revista de Sociologia da UFSCar, v. 9, n. 3, set.- dez. 2019, pp. 943-962. 